\title{
Atypical antipsychotics in the treatment of pathological aggression in children and adolescents: literature review and clinical recommendations
}

\author{
Antipsicóticos atípicos no tratamento da agressividade patológica em crianças e \\ adolescentes: revisão da literatura e recomendações clínicas
}

Eduardo Henrique Teixeira, ${ }^{1}$ Antonio Jacintho, ${ }^{2}$ Heloisa Valler Celeri, ${ }^{3}$ Paulo Dalgalarrondo ${ }^{4}$

\begin{abstract}
Objective: To review the literature about the use of atypical antipsychotics in the treatment of pathological aggression in children and adolescents.

Method: The databases MEDLINE, SciELO, and LILACS were searched for publications in Portuguese or English from 1992 to August 2011 using the following keywords: mental disease, child, adolescent, treatment, atypical antipsychotic, aggressive behavior, aggression, and violent behavior.

Results: Sixty-seven studies of good methodological quality and clinical interest and relevance were identified. Studies including children and adolescents were relatively limited, because few atypical antipsychotics have been approved by the Food and Drug Administration (FDA). All the medications included in this review (risperidone, olanzapine, quetiapine, ziprasidone, aripiprazole and clozapine) have some effectiveness in treating aggression in children and adolescents, and choices should be based on clinical indications and side effects.

Conclusions: There are few studies about the effectiveness and safety of atypical antipsychotics for the pediatric population, and further randomized controlled studies with larger groups of patients and more diagnostic categories, such as severe conduct disorder and oppositional defiant disorder, should be conducted to confirm the results reported up to date and to evaluate the impact of long-term use.
\end{abstract}

Keywords: Aggression, violence, atypical antipsychotics, behavioral disorders, children, adolescents.

\begin{abstract}
Resumo
Objetivo: Realizar uma revisão sistemática da literatura científica sobre o uso de antipsicóticos atípicos (APAs) no tratamento da agressividade patológica em crianças e adolescentes.

Método: Foi realizada busca eletrônica nas bases de dados MEDLINE, SCiELO e LILACS, de 1992 a agosto 2011, considerando artigos publicados em língua inglesa e portuguesa. Foram utilizadas associações das seguintes expressões: mental disease, child, adolescent, treatment, atypical antipsychotic, aggressive behaviour, aggression e violent behavior.

Resultados: Foram identificados 67 artigos de boa qualidade metodológica, de relevância e interesse clínico para o tema em foco. De modo geral, os estudos são relativamente limitados para esta faixa etária, resultado do fato de poucos APAs terem sido aprovados pela Food and Drug Administration (FDA). Dentre as medicações consideradas nesta revisão (risperidona, olanzapina, quetiapina, ziprazidona, aripiprazol e clozapina), todas elas podem ter alguma efetividade no tratamento da agressividade em crianças e adolescentes, ficando a escolha baseada na indicação clínica e perfil de efeitos colaterais.

Conclusão: $O$ número ainda limitado de estudos acerca da efetividade e segurança na população pediátrica demanda pesquisas futuras com grupos maiores de pacientes e com mais categorias diagnósticas (como, por exemplo, as formas graves de transtorno de conduta e transtorno desafiador de oposição), desenhadas de forma randomizada e controlada. Assim poderão ser confirmados os achados até o momento e o impacto do uso em longo prazo.
\end{abstract}

Descritores: Agressão, violência, agentes antipsicóticos, transtornos do comportamento, infância, adolescência.

\footnotetext{
${ }_{1}^{1}$ Psychiatrist, specialist in Forensic Psychiatry. MSc and PhD in Psychiatry, School of Medical Sciences, Universidade Estadual de Campinas (UNICAMP), Campinas, SP, Brazil. Professor, School of Medicine, Pontifícia Universidade Católica de Campinas (PUC-Campinas), Campinas, SP, Brazil. ${ }^{2}$ Psychiatrist, specialist in Child and Adolescent Psychiatry. Head of the Child and Adolescent Psychiatry Outpatient Unit at Hospital de Clínicas da Universidade Estadual de Campinas (HC-Unicamp), Campinas, SP, Brazil. ${ }^{3}$ Psychiatrist, specialist in Child and Adolescent Psychiatry. Head of the Child and Adolescent Psychiatry Outpatient Unit at HC-Unicamp, Campinas, SP, Brazil. Professor, Department of Medical Psychology and Psychiatry, School of Medical Sciences, UNICAMP, Campinas, SP, Brazil. ${ }^{4}$ Psychiatrist. Professor, Department of Medical Psychology and Psychiatry, School of Medical Sciences, UNICAMP, Campinas, SP, Brazil.

Financial support: none.

Submitted Jan 30 2011, accepted for publication Jul 02 2012. No conflicts of interest declared concerning the publication of this article.

Suggested citation: Teixeira EH, Jacintho A, Celeri HV, Dalgalarrondo P. Atypical antipsychotics in the treatment of pathological aggression in children and adolescents: literature review and clinical recommendations. Trends Psychiatry Psychother. 2013;35(3):151-9.
} 


\section{Introduction}

Pathological aggression or morbid aggressive behaviors may be symptoms of numerous mental disorders that affect children and adolescents. It is the main cause of visits to psychiatric emergence services and of hospitalizations of children and adolescents in specialized psychiatric wards..$^{1-3}$ It is classified as a psychopathological symptom when not an adaptive behavior, as well as when it clearly clashes with cultural standards of the social group to which the child or adolescent belongs. ${ }^{4}$

Neurobiologically, impulsive/affective aggression may be explained as a lack of equilibrium between prefrontal mechanisms of top-down control (orbitofrontal cortex and anterior gyrus cinguli) and the bottom-up limbic stimuli (amygdala and other limbic areas), in which several neurotransmitters, such as serotonin, dopamine, noradrenalin and others, may be involved and may, therefore, be managed pharmacologically. ${ }^{5,6}$

Several studies have demonstrated that aggression is a result of the combination of socioenvironmental, psychological and biological factors, and that an environment favorable to personal development may modulate unfavorable genetic characteristics. ${ }^{7,8}$ However, biological factors of aggressive behaviors may and should be carefully managed because of probable mid- and long-term impairments and the progression into severe psychiatric disorders in adulthood. ${ }^{9-11}$

Clinically, aggression is usually approached in one of two ways: primarily approaching the underlying psychiatric disorder, or directly approaching the aggressive behavior as the main clinical sign of the outlying disorder and the main treatment target. ${ }^{12}$

According to Pappadopulos et al., $40 \%$ of the children and adolescents hospitalized and receiving treatment to control aggression were administered two or more drugs, and most often one of them as an atypical antipsychotic (AAP). Other drugs used were anticonvulsants, lithium, psychostimulants, selective serotonin reuptake inhibitors (SSRI), anxiolytics, alpha-agonists, beta-blockers and other sedative drugs. ${ }^{13}$

This study reviewed the scientific literature to analyze studies about pharmacological treatments using AAP for impulsive and affective aggression in children and adolescents, regardless of their underlying disease and the different treatments of this symptom, and to describe results and possible limitations. Moreover, at the end of the review, the authors make clinical suggestions that may be useful for healthcare professionals involved in providing mental health care to children and adolescents.

Predatory or proactive aggression has not been included in this study because it has a different meaning and demands a specific approach, different from the one used for impulsive or affective aggression. So far, studies have found little evidence of the benefits of pharmacological interventions in predatory aggression, which is more often found in environments of the justice system. ${ }^{12}$

Up to the time when this study was written, no review of this topic had been found in the literature. Therefore, this review may be useful as a basis for the use of AAP in the psychiatric and pediatric clinical practice.

\section{Method}

MEDLINE, SciELO and LILACS databases were searched for articles in English or Portuguese published from 1992 to August 2011. The search included studies about pharmacological treatments of aggression in the different diseases and syndromes that affect children and adolescents.

Combinations (AND, OR, NOT) of the following keywords were used for the search: mental disease, child, adolescent, treatment, atypical antipsychotic, aggressive behavior, aggression, violent behavior.

Although the number of studies about the use of antipsychotic drugs for children and adolescents has increased, few controlled studies have been conducted, because of the high withdrawal rates, short duration of interventions, and sample selection biases. ${ }^{14}$ Some studies with adults have been used as the basis for the initial tests with children and adolescents, but our review classified them only as parameters for a careful analysis of results, particularly for topics still not studied in the pediatric population, such as the risk of metabolic changes. ${ }^{15}$

Of the 77 studies retrieved, 67 were selected because of their higher methodological quality and greater relevance and clinical interest for the topic under study. The studies were selected by all the authors together, and all had access to abstracts. After that, the full articles were divided into two groups: clinical results and adverse events.

Inclusion criteria were: 1) randomized, placebo controlled studies; 2) case reports of children and adolescents, or of adults that were used as the basis for the administration of AAP to children and adolescents; 3) review of studies about aggression and its treatment.

This review did not establish grades of evidence (as defined by task forces), but only identified differences between controlled clinical studies (randomized, doubleblind), case series reports and clinical experience (lowest level of consistency). 


\section{Results}

Overall, the predominant view is that educational and psychosocial approaches should be implemented first and should not be discontinued after the introduction of medication. ${ }^{13,16}$

At the same time, the first medication used should be directed to the primary diagnosis, and only one drug should be used whenever possible. In the case of nonsuccess and when there are risks to the patients or the people that live with them, the treatment should include approaches directed to the aggressive behavior specifically. ${ }^{12,17-19}$

The use of psychopharmacologic drugs for patients in this age group should take into consideration the characteristic of their metabolism, drug pharmacokinetics and pharmacodynamics, and the risk of specific drug interactions. Children and adolescents, in general, are rapid metabolizers and, therefore, need antipsychotic doses that are proportionally higher in relation to their weight. ${ }^{20}$

Despite a significant increase in the use of AAP for children and adolescents in the last years, ${ }^{21}$ up to the time this study was concluded only four AAP had its use in the pediatric population approved by the Food and Drug Administration (FDA) (latest update on August 2011, according to www.fda.gov), as shown in the table below (Table 1 ).

Although not recommended by FDA, the first four AAP in Table 1 have been studied by several authors in the last decade. They investigated the control of aggression in conduct disorder and classified these medications as safe and efficient despite their side effects and the limitations of their studies. ${ }^{22}$

The use of AAP should be seen as a first tool to control aggression when non-pharmacological approaches fail. ${ }^{13}$ Several studies have compared the use of AAP and typical antipsychotics (TAP) in adolescents and young individuals and found that AAP should be the first choice because they have fewer side effects and lower risks of tardive dyskinesia, neuroleptic malignant syndrome, cognitive impairments and extrapyramidal symptoms (EPS), ${ }^{23-25}$ although the consequences of the metabolic and endocrine changes due to the use of AAP have not been clarified, especially not in children and adolescents. ${ }^{1}$

According to the November 2003 consensus of the American Association of Psychiatry and the American associations of endocrinologists and the associations for the study of diabetes and obesity, AAP had a clear benefit in psychiatric treatments. However, caution was recommended, and its use should be constantly monitored because of the risks of metabolic and hormonal disorders and weight gain. ${ }^{26}$

Studies have not found differences in the response to treatment between different AAP, and the choice of a specific drug should be based on patient tolerability and adverse events, the most common of which are weight gain, drowsiness, EPS and hyperprolactinemia. ${ }^{27}$ All AAP may cause drowsiness, particularly at high doses, and, because of that, AAP should be carefully administered: the dose should be accurately adjusted, and its toxicity and drug interactions should be re-evaluated at short time intervals. ${ }^{28}$

Although the occurrence of EPS due to the use of AAP among young patients is not negligible, it is less frequent than that of TAP. ${ }^{29}$ In studies designed to investigate schizophrenia starting in childhood, among AAPs, clozapine and quetiapine have been associated with lower rates of EPS, similarly to what is observed among adults. ${ }^{30,31}$

According to the Treatment Recommendations for the Use of Antipsychotics for Aggressive Youth (TRAAY), based on studies available and specialist consensus, treatment should begin with low doses that are then increased gradually, and its efficacy should be evaluated at the most two weeks later. In the case of risperidone, the mean dose

Table 1 - Atypical antipsychotics approved for use in children and adolescents by the FDA and the Brazilian ANVISA and their indications

\begin{tabular}{|c|c|c|c|c|c|c|c|c|}
\hline \multirow[t]{2}{*}{ Drugs } & \multicolumn{2}{|c|}{$\begin{array}{c}\text { Schizophrenia } \\
\text { (13-17 year-olds) }\end{array}$} & \multicolumn{2}{|c|}{$\begin{array}{c}\text { Bipolar affective disorder } \\
\text { (10-17 year-olds) }\end{array}$} & \multicolumn{2}{|c|}{$\begin{array}{l}\text { Irritability in } \\
\text { autism }\end{array}$} & \multicolumn{2}{|c|}{$\begin{array}{l}\text { Conduct } \\
\text { disorder* }\end{array}$} \\
\hline & FDA & ANVISA & FDA & ANVISA & FDA & ANVISA & FDA & ANVISA \\
\hline Risperidone & + & + & + & + & $\begin{array}{c}+ \\
(5-16)\end{array}$ & $\begin{array}{c}+ \\
(5-16)\end{array}$ & - & - \\
\hline Aripiprazole & + & + & + & + & $\begin{array}{c}+ \\
(6-17)\end{array}$ & $\begin{array}{c}+ \\
(6-17)\end{array}$ & - & - \\
\hline Olanzapine & + & + & $\begin{array}{c}+ \\
(13-17)\end{array}$ & $\begin{array}{c}+ \\
(13-17)\end{array}$ & - & - & - & - \\
\hline Quetiapine & + & + & + & + & - & - & - & - \\
\hline Clozapine & - & - & - & - & - & - & - & - \\
\hline
\end{tabular}

ANVISA $=$ Brazilian National Health Surveillance Agency; FDA $=$ U.S. Food and Drug Administration.

* Neither FDA nor ANVISA has any regulation about the use of drugs for the diagnostic category conduct disorder or to control aggression for any undefined diagnosis. 
Atypical antipsychotics to treat pathological aggression - Teixeira et al.

Table 2 - Differences between atypical antipsychotic active doses and the impact on aggression and psychotic symptoms

\begin{tabular}{|c|c|c|c|c|c|}
\hline \multirow[b]{2}{*}{ Drugs } & \multirow[b]{2}{*}{ Starting dose (mg) } & \multicolumn{2}{|c|}{ Aggression } & \multicolumn{2}{|c|}{ Psychotic symptoms } \\
\hline & & Child & Adolescent & Child & Adolescent \\
\hline Risperidone & $0.25-0.5$ & $1.5-2$ & $2-4$ & $3-4$ & $3-6$ \\
\hline Clozapine & $6.5-25$ & $150-300$ & $200-600$ & $150-300$ & $200-600$ \\
\hline
\end{tabular}

Source: Adapted from TRAAY-II, table 3 of Pappadopulos et al. ${ }^{13}$

to control aggression is smaller than (about half) the dose necessary to control psychotic symptoms, differently from clozapine, in which case the mean dose to treat aggression is similar to that of antipsychotic drugs, as seen in Table 2. Data about ideal doses to control aggression are not available for other AAP (Table 2). ${ }^{13}$

Studies about AAP are still limited, and, therefore, special attention should be paid to possible adverse events and interactions with other medications. Still according to the TRAAY Part II recommendations, vital signs, weight, prolactin levels and metabolic changes should be constantly monitored, and ECG should be used to monitor patients at regular intervals during dose adjustment, because cardiac changes are dosedependent. ${ }^{13,32}$

In the analysis of metabolic changes (weight gain, risk of diabetes and dyslipidemia), studies with adults found that there are differences between the several AAP medications, although results are still relatively discordant, according to Table $3 .^{26}$

\section{Risperidone}

Two double-blind studies with children and adolescents, one with a group of individuals with conduct disorder and the other with conduct disorder associated with subaverage intelligence, compared risperidone and placebo and found that risperidone is a well-tolerated and efficacious medication for aggression. ${ }^{33,34}$

Those studies found that the most common adverse events were drowsiness, headache and weight gain. The symptoms of aggression were controlled in 3 to 4 weeks using a mean dose of $1.5 \mathrm{mg} /$ day, which was effective in the control of aggression for the next six months when compared with the placebo group. 22,33,34

In the analysis of safety of its use for long periods of time, five studies investigated the use of risperidone in a total of 700 children and adolescents aged 5 to 15 years and found no influence on growth or sexual maturity, although there were changes in the levels of prolactin. ${ }^{35}$

A retrospective study including 80 individuals with autism who used risperidone to control aggression or impulsivity found that over $60 \%$ had a positive result after six months of treatment. The most common adverse effect was weight gain, followed by drowsiness, the adverse event most often associated with treatment discontinuation. ${ }^{36}$

A review ${ }^{37}$ has demonstrated that these findings are confirmed in double-blind, placebo-controlled studies and case reports of autism and pervasive developmental disorders, in which aggression was a relatively serious symptom. In a double-blind study with 101 children with autism who were administered a mean dose of $1.8 \mathrm{mg} /$ day of risperidone, $69 \%$ of the children were classified as responders after eight weeks, whereas only $12 \%$ in the placebo group responded satisfactorily. The most common adverse event was weight gain and hypersalivation, and there were no differences in EPS and tardive dyskinesia between groups. ${ }^{38}$ Similar results were found in a placebo-controlled study with 79 children, in which the mean dose was $1.2 \mathrm{mg} /$ day. ${ }^{39}$

The comparison with other AAPs revealed that risperidone was the medication that resulted in the highest prolactin elevation among adults with schizophrenia $(n=$ 218 ) in a study that followed up patients for five years. ${ }^{40}$

Table 3 - Atypical antipsychotics and risk of secondary metabolic changes in adults

\begin{tabular}{lccc}
\hline Drugs & Weight gain & Risk of diabetes & Worsened lipid profile \\
\hline Clozapine & +++ & + & + \\
Olanzapine & +++ & + & + \\
Risperidone & ++ & $\mathrm{D}$ & $\mathrm{D}$ \\
Quetiapine & ++ & $\mathrm{D}$ & $\mathrm{D}$ \\
Aripiprazole & $+/-$ & - & - \\
Ziprasidone & $+/-$ & - & - \\
\hline
\end{tabular}

Source: Consensus Development Conference on Antipsychotic Drugs and Obesity and Diabetes, $2004 .^{26}$

* New drugs with limited long-term follow-up studies.

+ = increase; - = no effect; $D=$ discordant results. 


\section{Olanzapine}

An open-label prospective trial was conducted with 16 adolescents with disruptive behavioral disorders and subaverage intelligence. Olanzapine was effective in the control of irritability when used at a mean dose of 13.7 $\mathrm{mg} /$ day, but weight gain led to treatment discontinuation in 4 of the 16 cases. ${ }^{41}$

Similar findings were reported in a review of medical charts of 23 adolescents with conduct disorder and no response to other treatments. Olanzapine was efficacious in $60 \%$ of the patients, and the most common adverse events were weight gain and sedation. ${ }^{42} \mathrm{~A}$ double-blind, open-label prospective study of aggression control in autism and other autistic disorders found similar results. ${ }^{43}$

In a study that compared the use of olanzapine with that of haloperidol in 12 children with autism for six weeks, olanzapine was more efficacious in the control of aggression, but resulted in greater weight gain. ${ }^{44}$

In some emergency situations that require aggression control, the IM injection of a rapid-acting medication may be necessary. Ziprasidone and olanzapine may be used in such cases, and their safety and efficacy has been demonstrated for use in adults in randomized double-blind studies. ${ }^{45,46}$ However, no data from clinical controlled studies are available to support the IM administration of AAP to children and adolescents.

\section{Quetiapine}

A study conducted by Findling et al. with 17 moderately aggressive children with a diagnosis of conduct disorder for 8 weeks found that quetiapine was efficacious and well tolerated at a mean dose of $150 \mathrm{mg} /$ day. The most frequent adverse events were fatigue and weight gain. No EPS or changes in prolactin levels were found during the study, ${ }^{47}$ which continued with nine children for another 26 weeks. Positive results in the control of aggression were seen along all this time, and mean weight gain was $2.3 \mathrm{~kg} .{ }^{48}$

An open-label prospective study with 24 aggressive adolescents with a diagnosis of attention deficit hyperactivity disorder and conduct disorder, who did not respond satisfactorily to treatment with methylphenidate alone, found that $79 \%$ improved their pattern of aggression when administered a maximum dose of $600 \mathrm{mg} / \mathrm{day}$. The most common adverse event was drowsiness, and mean weight gain was $1.2 \mathrm{~kg}$ after nine weeks. ${ }^{49}$

The results of quetiapine in the control of aggression in autism have been heterogeneous. In an open-label study with six children receiving a mean dose of 225 $\mathrm{mg} /$ day for four months, only two had improvements in their pattern of aggression. ${ }^{50}$ Another open-label study with nine adolescents used doses of 100 to $450 \mathrm{mg} /$ day for 12 weeks. Only six adolescents completed the study, and only two of them were responders in the analysis of aggression. ${ }^{51}$ In the two studies, the most common adverse events were drowsiness and weight gain, the reasons why three patients discontinued treatment.

\section{Ziprasidone}

Few studies have been published about the use of ziprasidone in children and adolescents. In a case series with 12 children with autism or other autistic disorders who received doses of 20 to $120 \mathrm{mg} /$ day for at least six weeks, six children were responders for the control of aggression, as well as of agitation and irritability. Sedation was the most common adverse event, and weight gain was found in only one child. Five children lost weight, which was associated with the discontinuation of previous medication that had resulted in weight gain. ${ }^{52}$

For emergency situations in the control of aggression, ziprasidone has an additional resource, which is an IM rapid-acting formulation, as described above, ${ }^{45}$ although no controlled studies or clinical reports have evaluated its use in children or adolescents.

\section{Aripiprazole}

In a case series with five children and adolescents with autism who received doses of 10 to $15 \mathrm{mg} /$ day for a mean time of 12 weeks, all five were judged responders for aggression control, as well as for agitation and irritability. Sedation was a transient adverse event, and weight changes were variable: two children lost weight, which was associated with the discontinuation of previous medication that had resulted in weight gain. ${ }^{53}$

Similar results were replicated in another case series with 32 children and adolescents with a diagnosis of autism, autistic disorders and mental retardation, who received a mean dose of $10.55 \mathrm{mg} /$ day for six to 15 months. There was a reduction in target symptoms (aggression, impulsivity, hyperactivity and self-injury) in $56 \%$ of the cases. Sedation was the most frequent adverse effect, and there were no significant changes in body weight. ${ }^{54}$

\section{Clozapine}

Few studies have evaluated the use of clozapine, particularly because of the risk of agranulocytosis and the need of rigorous monitoring of blood cell counts, which is a laborious task because of the little collaboration of children and adolescents, depending on their disease. ${ }^{37}$ 
In an open-label study about the impact of clozapine on treatment-refractory aggression in 20 children and adolescents with schizophrenia, the use of emergency medication and seclusion events were analyzed after the introduction of clozapine and compared with the previous period of time. Clozapine had greater efficacy than other AAP or TAP. Patients were evaluated for at least six months, and mean clozapine dose on the 12th week was $405 \mathrm{mg} /$ day. The study found a decrease in the frequency of administration of injectable medication and seclusion. ${ }^{55}$

Two series of case reports of patients with autism and severe treatment-refractory aggression previously receiving other medications found that clozapine was efficacious for most cases when administered at mean doses of 200 and $400 \mathrm{mg} /$ day. In the first study, three patients aged 8 to 12 years had a significant improvement of aggression, hyperactivity and irritability with the administration of 100 to $200 \mathrm{mg} /$ day. In the second study, the pattern of aggression improved for a 17-year-old patient receiving a mean final dose of $275 \mathrm{mg} /$ day. The major adverse events in the three studies were drowsiness, constipation, weight gain and hypersalivation. ${ }^{56,57}$

The analysis of the risk of agranulocytosis suggests that children may run a greater risk than adults. ${ }^{58}$ In an open-label retrospective study with 172 children (schizophrenia: 139; bipolar disorder: 25; others: 2) using clozapine, $13 \%$ had neutropenia, and one, agranulocytosis. In the same study, the most common adverse events were weight gain and changes in lipid metabolism. ${ }^{59}$

The safety of clozapine in relation to the levels of prolactin in children and adolescents was greater than that of other AAPs. A double-blind study with 35 children and adolescents with a diagnosis of schizophrenia compared clozapine with haloperidol and olanzapine and found that the three substances increased the levels of prolactin, but clozapine led to increases that were still within normal levels. After six weeks of treatment, all ten patients receiving haloperidol had increases above the normal limits, and seven of the ten using olanzapine had similar increases, but none of the 15 patients using clozapine had increases above the normal range. ${ }^{32}$

According to current TRAAY recommendations, if all other treatment options fail to control severe aggression, the use of clozapine should be considered in cases of schizophrenia and bipolar disorder in children and adolescents, despite the fact that clozapine has not yet been approved by FDA for use in these two age groups. There are no explicit recommendations for its use, and it has not even been studied for aggression in severe conduct disorders, although its potential usefulness seems plausible because of data from studies with other diagnostic groups. ${ }^{13,60,61}$ Pappadopulos et al. suggested that, if the response is only partial, the combination of clozapine and a mood stabilizer should be considered. However, such recommendation is not supported by studies with children and adolescents specifically. ${ }^{13}$

Table 4 shows data about the scientific studies included in this review, which administered AAP to children and adolescents to control aggression. The studies were divided into case reports, open-label trials and controlled (randomized or double-blind) studies.

\section{Discussion}

The treatment of pathological aggression, both in clinical practice and in research, is a great challenge, particularly when in its severe or extreme forms in children and adolescents. The establishment of an adequate and accurate psychiatric diagnosis, and therefore, the administration of the best possible treatment, involves a considerable degree of complexity. In these age groups, ethical issues regarding the treatment of people still in a stage of full development and who still have to be legally represented by their guardians becomes particularly difficult, complex and a matter of concern for clinicians.

The studies included in this review, particularly those conducted with children and adolescents, have several limitations as a consequence of that, in addition to the effects of comorbidities, multiplicity of drugs taken, and the necessary association with other therapeutic approaches, such as parental guidance, psychoeducation, institutional and environmental management, legal counseling and others.

The limitations of clinical and research results are associated with the small number of patients, who are usually studied in case series reports, with the heterogeneity of the diagnostic groups under study, with the short follow-up time ${ }^{14}$ and, finally, with the large dependence on adult clinical data and psychopharmacology, as the psychiatry of children and adolescents often only "borrows" data from adult psychiatry because it has not yet autonomously generated consistent knowledge based on original and carefully conducted studies. Despite these limitations, these studies allow us to reach some tentative conclusions.

The development of more modern and safer medications has given rise to different ways to deal with the aggressive behaviors of children and adolescents. ${ }^{12}$ There does not seem to be any doubt about the use of medication as a necessary intervention, particularly in severe and extreme cases. Studies have already demonstrated that severe aggression may result in significant harm to patients 
Table 4 - Case reports, open-label trials or controlled studies about the use of atypical antipsychotic drugs in children and adolescents to control aggressive behaviors

\begin{tabular}{|c|c|c|c|c|c|c|}
\hline & Risperidone & Olanzapine & Quetiapine & Ziprasidone & Aripiprazole & Clozapine \\
\hline \multicolumn{7}{|c|}{ Schizophrenia } \\
\hline CR/OL & - & - & - & - & - & $\begin{array}{c}N=1 \\
(n=23)^{55}\end{array}$ \\
\hline CS & - & - & - & - & - & - \\
\hline \multicolumn{7}{|l|}{ Autism } \\
\hline CR/OL & - & $\begin{array}{c}N=2 \\
(n=8)^{43} \\
(n=12)^{44}\end{array}$ & $\begin{array}{c}N=2 \\
(n=6)^{50} \\
(n=9)^{51}\end{array}$ & $\begin{array}{c}N=1 \\
(n=12)^{52}\end{array}$ & $\begin{array}{c}N=2 \\
(n=5)^{53} \\
(n=32)^{54}\end{array}$ & $\begin{array}{c}N=2 \\
(n=3)^{56} \\
(n=1)^{57}\end{array}$ \\
\hline $\mathrm{CS} / \mathrm{OL}$ & $\begin{array}{c}N=3 \\
(n=80)^{36} \\
(n=101)^{38} \\
(n=79)^{39}\end{array}$ & - & - & - & - & - \\
\hline \multicolumn{7}{|c|}{ Conduct disorder } \\
\hline CR/OL & - & $\begin{array}{c}N=2 \\
(n=16)^{41} \\
(n=23)^{42}\end{array}$ & $\begin{array}{c}N=2 \\
(n=16)^{47} \\
(n=24)^{* 49}\end{array}$ & - & - & - \\
\hline CS & $\begin{array}{c}N=2 \\
(n=118)^{33} \\
(n=10)^{34}\end{array}$ & - & - & - & - & - \\
\hline \multicolumn{7}{|c|}{ Mental retardation } \\
\hline CR/OL & - & - & - & - & $+(n=18)$ & $+(n=8)$ \\
\hline CS & $+(N=1)$ & - & - & - & - & - \\
\hline
\end{tabular}

and their families and favor the development of serious psychiatric disorders in adulthood..$^{9,10}$

AAPs seem to be good tools, and there is evidence that they are safe medications for use in children and adolescents with different diagnosis, ${ }^{13,22-25}$ in addition to being effective in the control of aggression in adults. ${ }^{15,62-64}$

Studies with children and adolescents that used these medications, particularly for patients with schizophrenia and autism, reported favorable results. ${ }^{55,57,65}$ However, only longitudinal prospective studies will be able to demonstrate the real impact of AAP on this population, particularly in terms of metabolic and hormone changes ${ }^{1,26}$ associated with growth and development, although adverse events are well tolerated and manageable. ${ }^{27-29,66}$

Studies that analyzed metabolic changes, such as weight gain, dyslipidemia and the risk of diabetes, have recommended that these medications should be used carefully, and that a proactive attitude should be adopted, with systematic monitoring using laboratory tests, weight control and nutritional interventions. ${ }^{13,14,29,32}$

Studies about the treatment of pathological aggression, particularly severe or extreme forms of it, in children and adolescents, remain limited. Therefore, there are no solid scientific bases for clinical decisions at a higher degree of safety. However, this is a topic of strategic relevance and that should be broadly investigated. In addition to methodological issues, these studies raise both clinical and ethical research problems, as they involve children and adolescents.

Particularly important are the ethical and politicalideological issues that pharmacological control of severe pathological aggression raises in clinical practice and in research with children and adolescents. It should always be stressed that pharmacological interventions should mandatorily be combined with careful psychosocial evaluations and approaches, such as parental and family counseling, psychotherapy, psychoeducation, school guidance and environment management, interventions that should be, whenever possible, based on controlled studies that have evaluated their short- and long-term efficacy.

There are few randomized, double-blind studies specifically designed to evaluate aggression control in children and adolescents, particularly severe aggression and in individuals with autistic and conduct disorders.

\section{Recommendations and suggestions of psychopharmacological management}

All the medications included in this review (risperidone, olanzapine, quetiapine, ziprasidone, aripiprazole and clozapine) seem to have some degree of effectiveness 
for children and adolescents, despite the limitations discussed in the text. Except for clozapine, studies did not find differences in their potency, and choices should be based on their adverse events. ${ }^{27}$

The most common adverse events after the use of AAP were two: drowsiness and weight gain. Risperidone was more frequently associated with increases in prolactin levels, ${ }^{40}$ and the use of ziprasidone was only partially associated with weight gain. ${ }^{52}$ Data about quetiapine and aripiprazole are still too limited to provide a minimally consistent evaluation of their adverse events. ${ }^{47-51,53,54}$

As clozapine has a specific profile of action and adverse events, and its efficacy in treating aggression has already been demonstrated, ${ }^{15,55,64}$ it should become the focus of more detailed investigations. ${ }^{13,61,67}$ Case report findings are favorable for the control of aggression in patients with schizophrenia, autism and mental retardation. Adverse events have been monitored and controlled in a relatively safe way. ${ }^{56,57,59,62}$ Although clozapine has not been formally approved by FDA for use in children and adolescents, the clinical experience of the authors suggests that it may be an important tool in the control of severe or extreme aggression in cases in which the control of this symptom may be fundamental for successful planning and treatment. This is often the case of children and adolescents with severe forms of conduct disorders.

\section{Conclusion}

The limited number of studies about the efficacy and safety of AAP use in the pediatric population warrants future studies with larger groups of patients and more diagnostic categories, such as severe forms of conduct disorder and oppositional defiant disorder. Future studies may confirm findings reported to this date, as well as the impact of the use of these drugs in the long term.

\section{References}

1. Schur SB, Sikich L, Findling RL, Malone RP, Crismon ML, Derivan $A$, et al. Treatment recommendations for the use of antipsychotics for aggressive youth (TRAAY). Part I: a review. J Am Acad Child Adolesc Psychiatry. 2003;42:132-144.

2. Prado-Lima PA. Pharmacological treatment of impulsivity and aggressive behavior. Rev Bras Psiquiatr. 2009;31(Suppl 2):S58-65.

3. Garland AF, Hough RL, McCabe KM, Yeh M, Wood PA, Aarons GA. Prevalence of psychiatric disorders in youths across five sectors of care. J Am Acad Child Adolesc Psychiatry. 2001;40:409-18.

4. Jensen PS, Youngstrom EA, Steiner $H$, Findling RL, Meyer RE, Malone RP, et al. Consensus report on impulsive aggression as a symptom across diagnostic categories in child psychiatry: implications for medication studies. J Am Acad Child Adolesc Psychiatry. 2007;46:309-22.

5. Siever LJ. Neurobiology of aggression and violence. Am J Psychiatry. 2008;165:429-42.
6. Siegel A, Bhatt S, Bhatt R, Zalcman SS. The neurobiological bases for development of pharmacological treatments of aggressive disorders. Curr Neuropharmacol. 2007;5:135-47.

7. Bordin IA, Offord DR. Transtorno de conduta e comportamento anti-social. Rev Bras Psiquiatr. 2000;22(Supl II):12-15.

8. Mendes DD, Mari Jde J, Singer M, Barros GM, Mello AF. Study review of biological, social and environmental factors associated with aggressive behavior. Rev Bras Psiquiatr. 2009;31(Suppl 2):S77-85.

9. Nestor PG. Neuropsychological and clinical correlates of murder and other forms of extreme violence in a forensic psychiatric population. J Nerv Ment Dis. 1992;180:418-23.

10. Bernstein DP, Cohen P, Skodol A, Bezirganian S, Brook JS. Childhood antecedents of adolescent personality disorders. Am J Psychiatry. 1996;153:907-13.

11. Blair RJ, Peschardt KS, Budhani S, Mitchell DG, Pine DS. The development of psychopathy. J Child Psychol Psychiatry. 2006;47:262-76.

12. Soller MV, Karnik NS, Steiner H. Psychopharmacologic treatment in juvenile offenders. Child Adolesc Psychiatr Clin N Am. 2006;15:477-99.

13. Pappadopulos E, Macintyre Ii JC, Crismon ML, Findling RL, Malone RP, Derivan A, et al. Treatment recommendations for the use of antipsychotics for aggressive youth (TRAAY). Part II. J Am Acad Child Adolesc Psychiatry. 2003;42:145-61.

14. James AC. Prescribing antipsychotics for children and adolescents. Adv Psychiatr Treat. 2010;16:63-75.

15. Cohen SA, Underwood MT. The use of clozapine in a mentally retarded and aggressive population. J Clin Psychiatry. 1994;55:440-44.

16. Jensen PS. The role of psychosocial therapies in managing aggression in children and adolescents. J Clin Psychiatry. 2008;69(Suppl 4):37-42.

17. Rutter M, Taylor EA. Child and Adolescent Psychiatry. Massachusets: Blackwell Publishment; 2002.

18. Connor DF, Glatt SJ, Lopez ID, Jackson D, Melloni RH Jr. Psychopharmacology and aggression. I: a meta-analysis of stimulant effects on overt/covert aggression-related behaviors in ADHD. J Am Acad Child Adolesc Psychiatry. 2002;41:253-61.

19. Heyneman EK. The aggressive child. Child Adolesc Psychiatr Clin N Am. 2003;12:667-77.

20. Brasil HH, Belisário Filho JF. Psicofarmacoterapia. Rev Bras Psiquiatr. 2000;22(Supl II):42-7.

21. Olfson M, Blanco C, Liu L, Moreno C, Laje G. National trends in the outpatient treatment of children and adolescents with antipsychotic drugs. Arch Gen Psychiatry. 2006;63:679-85.

22. Findling RL. Atypical antipsychotic treatment of disruptive behavior disorders in children and adolescents. J Clin Psychiatry. 2008;69(Suppl 4):9-14.

23. Campbell M, Armenteros JL, Malone RP, Adams PB, Eisenberg ZW, Overall JE. Neuroleptic-related dyskinesias in autistic children: a prospective, longitudinal study. J Am Acad Child Adolesc Psychiatry. 1997;36:835-43.

24. Toren $\mathrm{P}$, Laor N, Weizman A. Use of atypical neuroleptics in child and adolescent psychiatry. J Clin Psychiatry. 1998;59:644-56.

25. Gilberg C. Typical neuroleptics in chil and adolescent psychiatry. Eur Child Adolesc Psychiatry. 2000;9(Suppl I):2-8.

26. American Diabetes Association, American Association of Clinical Endocrinologists, North American Association for the Study of Obesity. Consensus development conference on antipsychotic drugs and obesity and diabetes. Diabetes Care. 2004;27:596-601.

27. Correll CU. Antipsychotic use in children and adolescents: minimizing adverse effects to maximize outcomes. J Am Acad Child Adolesc Psychiatry. 2008;47:9-20.

28. Correll CU. Assessing and maximizing the safety and tolerability of antipsychotics used in the treatment of children and adolescents. J Clin Psychiatry. 2008;69(Suppl 4):26-36.

29. Correll CU, Penzner JB, Parikh UH, Mughal T, Javed T, Carbon $M$, et al. Recognizing and monitoring adverse events of second-generation antipsychotics in children and adolescents. Child Adolesc Psychiatr Clin N Am. 2006;15:177-206. 
30. Kumra S, Frazier JA, Jacobsen LK, McKenna K, Gordon CT, Lenane MC, et al. Childhood-onset schizophrenia. A doubleblind clozapine-haloperidol comparison. Arch Gen Psychiatry. 1996;53:1090-7.

31. Shaw P, Sporn A, Gogtay N, Overman GP, Greenstein D, Gochman $P$, et al. Childhood-onset schizophrenia: a doubleblind, randomized clozapine-olanzapine comparison. Arch Gen Psychiatry. 2006;63:721-30.

32. Wudarsky $M$, Nicolson $R$, Hamburger SD, Spechler $L$, Gochman P, Bedwell J, et al. Elevated prolactin in pediatric patients on typical and atypical antipsychotics. J Child Adolesc Psychopharmacol. 1999;9:239-45.

33. Aman MG, De Smedt G, Derivan A, Lyons B, Findling RL. Double-blind, placebo-controlled study of risperidone for the treatment of disruptive behaviors in children with subaverage intelligence. Am J Psychiatry. 2002;159:1337-46.

34. Findling RL, McNamara NK, Branicky LA, Schluchter MD, Lemon $\mathrm{E}$, Blumer JL. A double-blind pilot study of risperidone in the treatment of conduct disorder. J Am Acad Child Adolesc Psychiatry. 2000;39:509-16.

35. Dunbar F, Kusumakar V, Daneman D, Schulz M. Growth and sexual maturation during long-term treatment with risperidone. Am J Psychiatry. 2004;161:918-20.

36. Lemmon ME, Gregas M, Jeste SS. Risperidone use in autism spectrum disorders: a retrospective review of a clinicreferred patient population. J Child Neurol. 2011;26:428-32.

37. McDougle CJ, Stigler KA, Erickson CA, Posey DJ. Atypical antipsychotics in children and adolescents with autistic and other pervasive developmental disorders. J Clin Psychiatry. 2008;69(Suppl 4):15-20.

38. McCracken JT, McGough J, Shah B, Cronin P, Hong D, Aman $M G$, et al. Risperidone in children with autism and serious behavioral problems. N Engl ] Med. 2002;347:314-21.

39. Shea S, Turgay A, Carroll A, Schulz M, Orlik H, Smith I, et al. Risperidone in the treatment of disruptive behavioral symptoms in children with autistic and other pervasive developmental disorders. Pediatrics. 2004;114:e634-41.

40. Eberhard J, Lindström E, Holstad M, Levander S. Prolactin level during 5 years of risperidone treatment in patients with psychotic disorders. Acta Psychiatr Scand. 2007;115:268-76.

41. Handen BL, Hardan AY. Open-label, prospective trial of olanzapine in adolescents with subaverage intelligence and disruptive behavioral disorders. J Am Acad Child Adolesc Psychiatry. 2006;45:928-35.

42. Masi G, Milone A, Canepa G, Millepiedi S, Mucci M, Muratori F. Olanzapine treatment in adolescents with severe conduct disorder. Eur Psychiatry. 2006;21:51-7.

43. Potenza MN, Holmes JP, Kanes SJ, McDougle CJ. Olanzapine treatment of children, adolescents, and adults with pervasive developmental disorders: an open-label pilot study. J Clin Psychopharmacol. 1999;19:37-44.

44. Malone RP, Cater J, Sheikh RM, Choudhury MS, Delaney MA. Olanzapine versus haloperidol in children with autistic disorder: an open pilot study. J Am Acad Child Adolesc Psychiatry. 2001;40:887-94.

45. Daniel DG, Potkin SG, Reeves KR, Swift RH, Harrigan EP. Intramuscular (IM) ziprasidone $20 \mathrm{mg}$ is effective in reducing acute agitation associated with psychosis: a double-blind, randomized trial. Psychopharmacology (Berl). 2001; 155:128-34.

46. Meehan K, Zhang F, David S, Tohen M, Janicak P, Small J, et al. A double-blind, randomized comparison of the efficacy and safety of intramuscular injections of olanzapine, lorazepam, or placebo in treating acutely agitated patients diagnosed with bipolar mania. J Clin Psychopharmacol. 2001;21:389-97.

47. Findling RL, Reed MD, O'Riordan MA, Demeter CA, Stansbrey RJ, McNamara NK. Effectiveness, safety, and pharmacokinetics of quetiapine in aggressive children with conduct disorder. J Am Acad Child Adolesc Psychiatry. 2006;45:792-800.

48. Findling RL, Reed MD, O'Riordan MA, Demeter CA, Stansbrey RJ, McNamara NK. A 26-week open-label study of quetiapine in children with conduct disorder. J Child Adolesc Psychopharmacol. 2007;17:1-9.
49. Kronenberger WG, Giauque AL, Lafata $D E$, Bohnstedt $B N$, Maxey LE, Dunn DW. Quetiapine addition in methylphenidate treatment-resistant adolescents with comorbid ADHD, conduct/oppositional-defiant disorder, and aggression: a prospective, open-label study. J Child Adolesc Psychopharmacol. 2007;17:334-47.

50. Martin A, Koenig K, Scahill L, Bregman J. Open-label quetiapine in the treatment of children and adolescents with autistic disorder. J Child Adolesc Psychopharmacol. 1999;9:99-107.

51. Findling RL, McNamara NK, Gracious BL, O'Riordan MA, Reed $M D$, Demeter $C$, et al. Quetiapine in nine youths with autistic disorder. J Child Adolesc Psychopharmacol. 2004; 14:287-94.

52. McDougle CJ, Kem DL, Posey DJ. Case series: use of ziprasidone for maladaptive symptoms in youths with autism. J Am Acad Child Adolesc Psychiatry. 2002;41:921-7.

53. Stigler KA, Posey DJ, McDougle CJ. Aripiprazole for maladaptive behavior in pervasive developmental disorders. J Child Adolesc Psychopharmacol. 2004;14:455-63.

54. Valicenti-McDermott MR, Demb $H$. Clinical effects and adverse reactions of off-label use of aripiprazole in children and adolescents with developmental disabilities. J Child Adolesc Psychopharmacol. 2006;16:549-60.

55. Kranzler H, Roofeh D, Gerbino-Rosen G, Dombrowski C, McMeniman M, DeThomas C, et al. Clozapine: its impact on aggressive behavior among children and adolescents with schizophrenia. J Am Acad Child Adolesc Psychiatry. 2005; 44:55-63.

56. Zuddas A, Ledda MG, Fratta A, Muglia P, Cianchetti C. Clinical effects of clozapine on autistic disorder. Am J Psychiatry. 1996; 153:738.

57. Chen NC, Bedair HS, McKay B, Bowers MB Jr, Mazure C. Clozapine in the treatment of aggression in an adolescent with autistic disorder. J Clin Psychiatry. 2001;62:479-80.

58. Gogtay N, Rapoport J. Clozapine use in children and adolescents. Expert Opin Pharmacother. 2008;9:459-65.

59. Gerbino-Rosen G, Roofeh D, Tompkins DA, Feryo D, Nusser L, Kranzler $\mathrm{H}$, et al. Hematological adverse events in clozapinetreated children and adolescents. J Am Acad Child Adolesc Psychiatry. 2005;44:1024-31.

60. Pappadopulos EA, Siennick SE, Jensen PS. Antipsychotics for aggressive adolescents: barriers to best practice. Expert Rev Neurother. 2003;3:85-98.

61. Findling RL, Frazier JA, Gerbino-Rosen G, Kranzler HN Kumra S, Kratochvil CJ. Is there a role for clozapine in the treatment of children and adolescents? J Am Acad Child Adolesc Psychiatry. 2007;46:423-8.

62. Gobbi G, Pulvirenti L. Long-term treatment with clozapine in an adult with autistic disorder accompanied by aggressive behaviour. J Psychiatry Neurosci. 2001;26:340-1.

63. Kraus JE, Sheitman BB. Clozapine reduces violent behavior in heterogeneous diagnostic groups. J Neuropsychiatry Clin Neurosci. 2005;17:36-44.

64. Smith $H$, White $T$. The effect of clozapine on the social behaviour schedule in patients attending a forensic psychiatry day hospital. Med Sci Law. 2004;44:213-6.

65. Sikich L. Efficacy of atypical antipsychotics in earlyonset schizophrenia and other psychotic disorders. J Clin Psychiatry. 2008;69(Suppl 4):21-5.

66. Correll CU. Metabolic side effects of second-generation antipsychotics in children and adolescents: a different story? J Clin Psychiatry. 2005;66:1331-2.

67. Stigler KA, McDougle CJ. Pharmacotherapy of irritability in pervasive developmental disorders. Child Adolesc Psychiatr Clin N Am. 2008;17:739-52.

\section{Correspondence}

Eduardo Henrique Teixeira

Rua Dona Rosa de Gusmão, 412, Guanabara

13073-141 - Campinas, SP - Brazil

Tel./Fax: + 55 (19) 3243.1374

E-mail: eduardo@psiquiatriaforense.com.br 